\title{
The effect of epidurally administered dexamethasone with lignocaine for post-operative analgesia in dogs un- dergoing ovariohysterectomy. A dose-response study ${ }^{1}$
}

Larissa Correa Hermeto', Rafael de Rossi", Natalia de Andrade Bicudo'", Klebs Tavares Assis"', Lucas Latta Escobar'v, Pedro Santana de Camargo'v

'PhD, Postdoctoral Student, Postgraduate Program in Veterinary Sciences, Veterinary Medicine and Animal Science School, Universidade Federal do Mato Grosso do Sul (UFMS), Campo Grande-MS, Brazil. Acquisition of data, conception and design of the study, technical procedures, statistical analysis, manuscript preparation and writing, critical revision. "PhD, Associate Professor, Anesthesiology and Surgery Division, Veterinary Medicine and Animal Science School, UFMS, Campo Grande-MS, Brazil. Scientific and intellectual content of the study, analysis and interpretation of data, final approval.

'"DVM, Department of Veterinary Medicine, Veterinary Medicine and Animal Science School, UFMS, Campo Grande-MS, Brazil. Technical procedures, statistical analysis.

IVDVM, Graduate student, Department of Veterinary Medicine, Veterinary Medicine and Animal Science School, UFMS, Campo Grande-MS, Brazil. Technical procedures, acquisition of data.

Abstract

Purpose: To evaluate the postoperative analgesic and adverse effects of three doses of dexamethasone, administered epidurally in combination with lignocaine, in dogs undergoing ovariohysterectomy (OVH).

Methods: Twenty-four female dogs undergoing ovariohysterectomy were pre-medicated with acepromazine and general anaesthesia was induced and maintained with propofol. Animals were randomly allocated into four groups of six. The control group was given lignocaine $2 \%(\mathrm{LI})$ and the treatment groups were given lignocaine with either $2 \mathrm{mg}$ dexamethasone (LIDEX2), $4 \mathrm{mg}$ dexamethasone (LIDEX4) or $8 \mathrm{mg}$ dexamethasone (LIDEX8) administered at the lumbosacral epidural space. Duration of postoperative analgesia, first analgesic rescue, motor blockade, heart rate, blood pressure, respiratory rate, and rectal temperature were evaluated.

Results: The duration of postoperative analgesia was 19.5 (SD 6) hours for LIDEX8 ( $p=0.001$ ), 10 (SD 2) hours for LIDEX4 ( $p=0.002), 4$ (SD 2) hours for LIDEX2 ( $p=0.074)$ treatments compared with values for the LI control treatment 2.2 (SD 1.6) hours. All treatments had significant cardiovascular and respiratory alterations but they were within acceptable range in these clinically healthy female dogs.

Conclusion: Dexamethasone added to epidural lignocaine significantly extends the postoperative analgesia after ovariohysterectomy in female dogs.

Key words: Dexamethasone. Lignocaine. Analgesia, Epidural. Pain. Dogs. 


\section{Introduction}

Inadequate postoperative pain relief can delay recovery and increase the incidence of adverse effects, such as delayed healing, lack of appetite and decreased immunity ${ }^{1}$. Female dogs undergoing ovariohysterectomy $(\mathrm{OVH})$ suffer pain of varying severity (mild-tomoderate) depending on the degree of surgical trauma, requiring analgesic drugs in the first postoperative day ${ }^{2}$. To increase the duration of analgesia, epidural techniques with local anaesthetics have been investigated in human and animal models in association with adjuncts such as opioids ${ }^{3}$, neostigmine ${ }^{4}$ and alpha $_{2}{ }^{-}$ agonists $^{5}$. Epidural opioids were found to be associated with nausea, vomiting, pruritus, urinary retention and respiratory depression in $\operatorname{dog}^{6,7}$, and epidural administration of alpha ${ }_{2}^{-}$ agonists produced hypotension, bradycardia and sedation in children and dogs $5^{5,8,9}$. These adverse effects might not be appropriate in weakened animals or those with systemic disorders.

Corticosteroids are used clinically for their anti-inflammatory and immunosuppressive activity, and they have been shown to reduce postoperative pain when administered by the epidural route after various surgeries in human patients ${ }^{10,11}$. The exact mechanism of this analgesic effect is not understood $^{12}$, but several mechanisms have been suggested to explain $i^{13,14}$. Inhibition of phospholipase A2 and cyclooxygenase-2 expression by steroids during inflammation reduces prostaglandin synthesis and subsequently decreases the hyperalgesia associated with acute nociception during surgery ${ }^{15}$. Dexamethasone phosphate (DEX) is a water soluble corticosteroid with high-potency and a long-acting glucocorticoid with little mineralocorticoid effect ${ }^{16}$. In humans, lumbar epidural dexamethasone has been used to treat patients with postoperative pain resulting from lower abdominal surgeries ${ }^{10,17}$, hysterectomy ${ }^{11}$ or orchiopexy and back pain ${ }^{1,18,19}$. The authors are unaware of any studies on the use of epidural dexamethasone in dogs to relieve pain and increase the duration of action of the lignocaine local anaesthetic in the postoperative period.

We hypothesized that dexamethasone with lignocaine by epidural route can improve the postoperative pain control in dogs. The primary purpose of this randomized blinded study was to evaluate the analgesic effects of three doses of dexamethasone when administered epidurally in combination with lignocaine for postoperative analgesia, and the secondary purpose was to evaluate the incidence of adverse effects of the epidural dexamethasone administration in female dogs undergoing $\mathrm{OVH}$.

\section{- Methods}

The experimental protocol of the present study was approved by the Ethics Committee for Animal Use, Universidade Federal do Mato Grosso do Sul, in accordance with the Good Clinical Practice guidelines.

The study involved 28 adult female dogs (ASA status I, normal healthy patients) aged 2-6 years and weighing mean 11 (SD 6) $\mathrm{kg}$ that were admitted to the Faculty of Veterinary Medicine and Animal Science facilities to be neutered. The study protocol and the epidural procedure were explained to each owner, and written consent was obtained. Female dogs were excluded if there was a contraindication to epidural anaesthesia (previous pelvic fractures, coagulopathy, local infection) or 
failure to achieve the epidural analgesia by the difficulty in locating the epidural space. Female dogs were also excluded if they were obese, because these animals are more susceptible to problems such as metabolic abnormalities, endocrinopathies, easier to have overdosing with anaesthetic drugs and animal's veins may be more difficult to locate and catheterize, or had received corticosteroids or immunosuppressive drugs in the last 6 months or had a contraindication to corticosteroids. All surgeries were performed by the same surgeon using midline approach with animal in dorsal recumbency and 3-hemostat technique, and did not take longer than 60 minutes.

\section{Experimental design}

Animals were randomly allocated on treatment analysis approach into one of four treatments ( $n=6$, for each treatment). Control animals were given a single epidural injection of lignocaine $2 \%$ without epinephrine (Treatment LI; $4.0 \mathrm{mg} / \mathrm{kg}$; Xylestesin 2\%, Cristália Chemical and Pharmaceutical Products, Itapira, BR). Animals in the other three treatment groups were given epidural injection of $2 \%$ lignocaine $(2.0 \mathrm{mg} / \mathrm{kg}$, mean dose $1.1 \mathrm{~mL})$ containing either $2 \mathrm{mg}$ dexamethasone phosphate (Treatment
LIDEX2, mean dose $0.8 \mathrm{~mL}$; Decadron 4 $\mathrm{mg} / \mathrm{mL}$, Aché Laboratórios Farmacêuticos S.A., Guarulhos, BR), 4 mg dexamethasone phosphate (Treatment LIDEX4, mean dose $1.4 \mathrm{~mL}$ ) or $8 \mathrm{mg}$ dexamethasone phosphate (Treatment LIDEX8, mean dose $1.6 \mathrm{~mL}$ ). The dexamethasone doses used in this experiment were based on previous studies in humans ${ }^{2,14,15}$. All physiological data were monitored: heart rate (HR); respiratory rate (RR); systolic (SAP), diastolic (DAP), and mean (MAP) arterial blood pressures; and rectal temperature (RT) at baseline $\left(T_{0}\right), 10$ minutes after premedication $\left(T_{10}\right)$, after the start of TIVA $\left(T_{20}\right)$, after epidural injections $\left(T_{30}\right), 60$ min after epidural injections $\left(T_{60}\right)$, and 120 min after epidural injections $\left(T_{120}\right)$. After epidural injections, the pain and movement assessments were performed at 1, 2, 4 and 6 hours and then at 6-hour intervals for 24 hours by a blinded observer, accustomed to scoring (Table 1). The nausea was evaluated by the presence of the vomiting anxiety, characterized by hypersalivation and an increase in the frequency of licking in order to coat the esophagus with bicarbonate-rich saliva preventing esophageal injury by stomach acid reflux. The presence or absence of nausea was assessed throughout the experimental period. 
Table 1 - Multidimensional composite pain score applied to female dogs subjected to epidural administration of lignocaine with and without the addition of dexamethasone phosphate after ovariohysterectomy.

\begin{tabular}{|c|c|c|}
\hline Observation & Score & Criteria \\
\hline \multirow[t]{4}{*}{ Response to stimuli } & 0 & $\begin{array}{l}\text { No response: dog does not react when the surgical wound is touched or } \\
\text { pressed }\end{array}$ \\
\hline & 1 & $\begin{array}{l}\text { Mild response: tense muscles, and dog moves slowly when the surgical wound } \\
\text { is touched }\end{array}$ \\
\hline & 2 & $\begin{array}{l}\text { Moderate response: tense muscles, and dog turns head and licks before or } \\
\text { after touch or pressure of the surgical wound }\end{array}$ \\
\hline & 3 & $\begin{array}{l}\text { Severe response: dog is restless, reacts quickly and acts aggressively toward } \\
\text { the evaluator when the wound is touched or pressed }\end{array}$ \\
\hline \multirow[t]{3}{*}{ Movement } & 0 & $\begin{array}{l}\text { Normal posture: standing, has head hanging down and moves spontaneously } \\
\text { inside and outside the cage }\end{array}$ \\
\hline & 1 & $\begin{array}{l}\text { Dogs in sternal or lateral recumbency or abnormal posture (prayer position, } \\
\text { hunched) }\end{array}$ \\
\hline & 2 & Dog does not move after being stimulated, inside or outside the cage \\
\hline \multirow[t]{4}{*}{ Vocalization } & 0 & Not vocalizing \\
\hline & 1 & Vocalizing when touched by the evaluator \\
\hline & 2 & Intermittent vocalization when stimulated by the evaluator \\
\hline & 3 & Continuous spontaneous vocalization, without being manipulated \\
\hline \multirow[t]{3}{*}{ Behavioural } & 0 & $\begin{array}{l}\text { Dog is submissive and interested in the environment and is friendly when } \\
\text { stimulated by the evaluator }\end{array}$ \\
\hline & 1 & $\begin{array}{l}\text { Slow reaction, wary; dog is not interested in the environment and does not } \\
\text { interact with the evaluator }\end{array}$ \\
\hline & 2 & Aggressive when handled or when stimulated by the evaluator \\
\hline \multirow[t]{3}{*}{ Return of appetite } & 0 & Eats normally during the postoperative period \\
\hline & 1 & Eats less during the postoperative period \\
\hline & 2 & Dog is not interested in food during the postoperative period \\
\hline \multicolumn{3}{|l|}{ Physiologic data } \\
\hline \multirow[t]{3}{*}{ Heart rate } & 0 & Normal (70-120 beats/min) \\
\hline & 1 & $\geq 20 \%$ above the values of the preoperative period \\
\hline & 2 & $\geq 50 \%$ above the values of the preoperative period \\
\hline \multirow[t]{3}{*}{ Respiratory rate } & 0 & Normal (15-35 breaths/min) \\
\hline & 1 & $\geq 20 \%$ above the values of the preoperative period \\
\hline & 2 & $\geq 50 \%$ above the values of the preoperative period \\
\hline \multirow[t]{2}{*}{ Mydriasis } & 0 & No \\
\hline & 1 & Yes \\
\hline \multirow[t]{2}{*}{ Rectal temperature } & 0 & Within the reference range \\
\hline & 1 & Above or below the reference range \\
\hline
\end{tabular}




\section{Physiological measurements}

Arterial blood pressures were measured through a multivariable analyser (Dixtal DX 2021; Dixtal Biomédica Ind e Com, Ltda, Manaus, BR) by using a noninvasive oscillometric device, with the cuff (width, $11.7-6.9 \mathrm{~cm}$ or $15-8.9 \mathrm{~cm}$ ) placed over the ulnar artery on the forearm. HR was measured using electrocardiography, RR was determined by observing the number of chest excursions during a 1 minute, and RT was obtained with a digital thermometer (Tech Line, Mesore Technology Co. Ltd, Dongting Town, $\mathrm{CH}$ ).

\section{Anaesthesia - induction \& maintenance procedures}

Female dogs were admitted to the hospital one day before surgical procedures. All animals were fasted overnight but had free access to water up to 1 hour before the time of premedication. Female dogs were premedicated with $0.05 \mathrm{mg} / \mathrm{kg}$ of acepromazine (Acepran 0.2\%; Univet S.A., São Paulo, Brazil) intramuscularly. The cephalic vein access was established using a 22-G intravenous cannula for the administration of $10 \mathrm{~mL} /$ $\mathrm{kg} / \mathrm{h}$ prophylactic Lactated Ringer's solution throughout the operation. All anaesthetic procedures, including endotracheal intubation and epidural injections were performed by the same blinded anaesthetist. Fifteen minutes after premedication administration, total intravenous anaesthesia (TIVA) was performed with propofol (Provive 1\%; Claris Injectable Ltd, Ahmedabad, IN) to effect $(4-6 \mathrm{mg} / \mathrm{kg}$, mean dose 60 (SD 11) mg), which was administered slowly via the cephalic catheter. Adequate anaesthesia was assessed using jaw tone, eye position, coughing reflex, and ocular-palpebral reflex, and the dose of propofol was altered accordingly. If the depth of anaesthesia was considered to be inadequate (increase in SAP,
DAP, MAP, HR or RR of $>15 \%$ of baseline values and somatic responses such as voluntary gross movements of the forelimbs and head or swallowing), a bolus of propofol ( $1 \mathrm{mg} / \mathrm{kg}$, IV) was administered.

\section{Epidural administration}

After anaesthesia induction, all animals were placed on a thermal bed (Styllus Term Produtos Térmicos, São Paulo, BR) in sternal recumbency with the pelvic limbs pulled forward. The lumbosacral region was identified, clipped and cleaned in an aseptic manner. A 19-G or 20-G, $8.1 \mathrm{~cm}$ Tuohy needle (Perican, B Braun, São Gonzalo, BR) was inserted into the lumbosacral epidural space (L7-S1). Proper needle positioning was confirmed by the hanging-drop method and lack of resistance upon injection of $0.5 \mathrm{~mL}$ of air. In all treatment groups, the total volume administered into the epidural space $(0.25 \mathrm{~mL} / \mathrm{kg})$ was achieved by the addition of sterile saline $0.9 \%$ (Halexistar, Indústria Farmacêutica, Goiânia, BR). All dogs were maintained in sternal position for at least 15 minutes after administration of the epidural drugs to allow adequate spread of the injectate within the epidural canal, then the animal was positioned in dorsal decubitus and the surgery was performed.

Pain score and motor function assessment

A combination of scores, based on previous studies ${ }^{20,21}$ that evaluated postoperative pain in small animals, was used, and the same blinded observer did all evaluations. The return of motor function was considered to have occurred when there was spontaneous movement of the pelvic limbs and presence of a pedal reflex after the epidural administration of lignocaine, according to the movement criteria in Table 1. Postoperative analgesia was evaluated, 
using a score composed of physiologic and behavioural parameters. The quality and duration of analgesia was measured with a multidimensional composite pain scale of $0-18$, on which 0 represented a complete lack of physiologic/behaviour(s) indicative of pain and 18 was the worst pain possible. In order to generate the total value of the pain score the sum of the criteria proposed in Table 1 was made. During this period the animals were kept in individual cages in the recovery room. Whenever the score was $\geq 6$, analgesia was provided by tramadol ( $4 \mathrm{mg} / \mathrm{kg}, \mathrm{IM}$ ) and ketoprofen $(2 \mathrm{mg} / \mathrm{kg}$, IM). If the score remained $>6$ at 20 minutes after administration of the first rescue analgesic, the female dogs were removed from the experiment and subsequent injections of morphine $(0.5 \mathrm{mg} / \mathrm{kg}$, IM) were administered until the pain score was $<6$. Other variables evaluated were nausea and vomiting.

After the first 24 hours of postoperative analgesic assessment, the female dogs were followed up in the out-patient department at 1 week after surgery by a veterinary surgeon for occurrence of adverse effects accompanying dexamethasone usage, such as wound infection or delayed wound healing. OVH scar healing and any inflammation or discharge from the wound was evaluated. To a better clinical evaluation of the surgical wound, we measured the wound swelling and a subjective manner the amount of redness and bruising.

\section{Statistical analysis}

Quantitative variables ( $\mathrm{HR}, \mathrm{RR}, \mathrm{SAP}$, DAP, MAP and RT) were analysed within and among groups by using analysis of variance (ANOVA) for repeated measures, and the post hoc Tukey method was applied. Analgesia and behavioural and ataxia variables (Table 1) were analysed within and among groups with the nonparametric Friedman's test. Statistical analyses were performed with Sigma Stat II (Systat Software Inc., San Jose, CA, USA). Data were grouped and summarized as mean \pm standard deviation and median and interquartile range (IQR) for nonparametric tested parameters. For all comparisons, $p<0.05$ was considered statistically significant.

\section{Results}

After randomization, no significant differences were observed among groups based on demographic data, age and weight, ASA categorization, hemodynamic and respiratory parameters, and duration of surgery (Table 2). Four dogs were excluded from the experiment because it was not possible to be sure that the epidural space was reached. All dogs regained motor function in all treatments in approximately 2 hours. All animals of all treatments that received dexamethasone epidural had a brief period of mild sedation clinically observed, after the return of motor function. Postoperative nausea was significantly less in the LI, LIDEX2 and LIDEX4 treatments versus the LIDEX8 treatment $(p=0.03)$. No female dogs experienced wound infection or delayed wound healing at followup after 1 week. Time to first analgesic rescue was prolonged in dexamethasone treatments, 19.5 (SD 6) hours for LIDEX8 ( $p=0.001), 10$ (SD 2) hours for LIDEX4 ( $p=0.002), 4$ (SD 2) hours for LIDEX2 $(p=0.074)$ treatments compared with values for the $\mathrm{LI}$ control treatment 2.2 (SD 1.6) hours (Figure 1). 
Table 2 - Demographic data and clinical variables.

\begin{tabular}{lllll} 
& \multicolumn{5}{c}{ Treatments } \\
Characteristics & LI $(\mathrm{n}=6)$ & LIDEX2 $(\mathrm{n}=6)$ & LIDEX4 $(\mathrm{n}=6)$ & LIDEX8 $(\mathrm{n}=6)$ \\
\hline Age $(\mathrm{yr})$ & $5 \pm 1$ & $3 \pm 1.5$ & $4 \pm 1.2$ & $4.3 \pm 1.0$ \\
Weight $(\mathrm{kg})$ & $10.4 \pm 3$ & $8.5 \pm 6.5$ & $10.2 \pm 4$ & $12.6 \pm 4$ \\
Dose total of propofol $(\mathrm{mg})$ & $56 \pm 11$ & $59 \pm 9$ & $61 \pm 7.5$ & $58.5 \pm 6$ \\
Dose of dexamethasone (mg/kg) & $\mathrm{N} / \mathrm{A}$ & $0.3 \pm 0.1$ & $0.5 \pm 0.1^{*}$ & $0.6 \pm 0.1^{\S,}{ }^{+}$ \\
Duration of surgery (minutes) & $25 \pm 3$ & $24 \pm 4$ & $25 \pm 6$ & $27 \pm 4$ \\
Motor blockade (minutes) & $48 \pm 7$ & $45 \pm 9$ & $52 \pm 6$ & $50 \pm 5$ \\
Nausea (\%) & $2(33 \%)$ & $1(16 \%)$ & $1(16 \%)$ & $3(50 \%)^{\ddagger}$ \\
First analgesic rescue (hours) & $2.2 \pm 1.6$ & $4 \pm 2$ & $10 \pm 2$ & $19.5 \pm 6$ \\
\hline
\end{tabular}

Treatment LI, control group; treatment LIDEX2, lignocaine+dexamethasone $2 \mathrm{mg}$ group; treatment LIDEX4, lignocaine+dexamethasone $4 \mathrm{mg}$ group; treatment LIDEX8, lignocaine+dexamethasone $8 \mathrm{mg}$ group; N/A, not applicable; Values are reported as mean \pm SD. Student's $t$-test $(p<0.05),{ }^{*} p=0,005$ relative to LIDEX2 treatment, ${ }^{\S} p=0,009$ relative to LIDEX2, ${ }^{\dagger} p=0,002$ relative to LIDEX4, ${ }^{\ddagger} p=0.03$ relative to LI, LIDEX2 and LIDEX4.

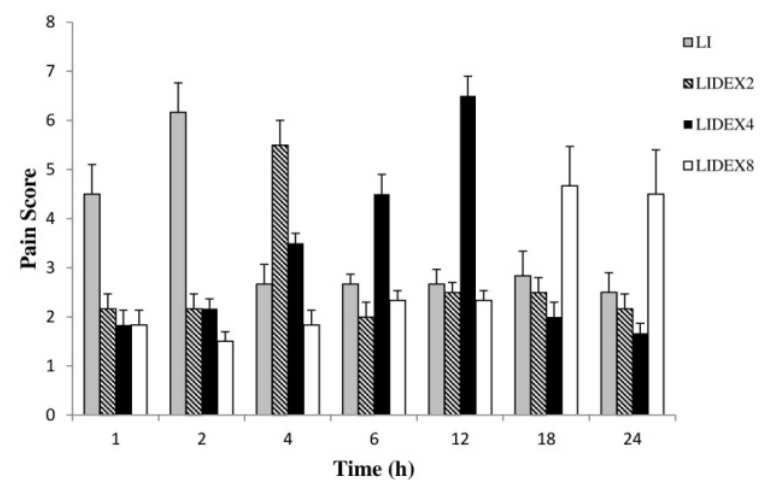

Figure 1 - Median pain score in twenty four bitches ( $n=6$, per treatment group) that underwent ovariohysterectomy with epidural administration of lignocaine $2 \%$ (LI, $4 \mathrm{mg} / \mathrm{kg}$ ), lignocaine $(2 \mathrm{mg} /$ $\mathrm{kg}$ ) plus $2 \mathrm{mg}$ dexamethasone (LIDEX2), lignocaine $(2 \mathrm{mg} / \mathrm{kg}$ ) plus $4 \mathrm{mg}$ dexamethasone (LIDEX4), or lignocaine $(2 \mathrm{mg} / \mathrm{kg})$ plus $8 \mathrm{mg}$ dexamethasone (LIDEX8) during a 24-hour period. Error bars represents the third quartile (IQR) at each given time period.
Female dogs in all treatment groups had changes in $H R, R R$ and arterial blood pressures as shown in the Table 3. HR was higher $(p=0.032)$ with the LIDEX8 treatment compared to the basal values at 10-30 minutes. The arterial pressures (SAP, DAP and MAP) were lower $(p=0.027)$ compared to the basal values following TIVA and epidural injections at 20-60 minutes in all treatments. RR decreased $(p=0.017)$ compared to the basal values from 20 to 30 minutes in the LI and LIDEX2 treatments. RT was lower $(p=0.03)$ compared to the basal values in the four treatments, which was from 30 to 120 minutes with the $\mathrm{LI}$ treatment and from 20 to 120 minutes with the LIDEX2, LIDEX4 and LIDEX8 treatments. 
Table 3 - Cardiovascular and respiratory rates and rectal temperature in female dogs undergoing ovaovariohysterectomy ( $\mathrm{n}=6 /$ treatment) receiving lidocaine $(\mathrm{LI}, 4.0 \mathrm{mg} / \mathrm{kg}$ ) or lidocaine $(2 \mathrm{mg} / \mathrm{kg}$ ) coccontaining dexamethasone $2 \mathrm{mg}$ (LIDEX2), $4 \mathrm{mg}$ (LIDEX4) or $8 \mathrm{mg}$ (LIDEX8) (mean \pm SD).

\begin{tabular}{|c|c|c|c|c|c|c|c|}
\hline & & Time (m & & & & & \\
\hline & Treatments & $\mathrm{T}_{0}$ & $T_{10}$ & $T_{20}$ & $T_{30}$ & $T_{60}$ & $\mathrm{~T}_{120}$ \\
\hline $\mathrm{HR}$ & $\mathrm{LI}$ & $125 \pm 3$ & $126 \pm 5$ & $125 \pm 5$ & $111 \pm 8$ & $112 \pm 8$ & $111 \pm 4$ \\
\hline & LIDEX2 & $117 \pm 5$ & $115 \pm 8$ & $118 \pm 6$ & $110 \pm 3$ & $106 \pm 5$ & $105 \pm 3$ \\
\hline & LIDEX4 & $105 \pm 4$ & $108 \pm 5$ & $101 \pm 10$ & $95 \pm 6$ & $107 \pm 5$ & $105 \pm 4$ \\
\hline & LIDEX8 & $102 \pm 6$ & $116 \pm 6^{*}$ & $117 \pm 7^{*}$ & $118 \pm 7^{*}$ & $110 \pm 6$ & $106 \pm 3$ \\
\hline $\mathrm{RR}$ & $\mathrm{LI}$ & $35 \pm 6$ & $36 \pm 4$ & $21 \pm 2 *$ & $21 \pm 3^{*}$ & $27 \pm 3$ & $27 \pm 1$ \\
\hline & LIDEX2 & $33 \pm 4$ & $33 \pm 4$ & $24 \pm 5^{*}$ & $18 \pm 1^{*}$ & $28 \pm 4$ & $26 \pm 3$ \\
\hline & LIDEX4 & $30 \pm 4$ & $27 \pm 5$ & $23 \pm 5$ & $22 \pm 2$ & $20 \pm 3$ & $20 \pm 2$ \\
\hline & LIDEX8 & $32 \pm 3$ & $33 \pm 5$ & $27 \pm 5$ & $23 \pm 4$ & $23 \pm 4$ & $24 \pm 2$ \\
\hline SAP & $\mathrm{LI}$ & $112 \pm 8$ & $106 \pm 5$ & $87 \pm 5^{*}$ & $80 \pm 7^{*}$ & $83 \pm 5^{*}$ & $105 \pm 3$ \\
\hline & LIDEX2 & $131 \pm 5$ & $128 \pm 6$ & $104 \pm 8^{*}$ & $78 \pm 4^{*}$ & $90 \pm 9^{*}$ & $127 \pm 3$ \\
\hline & LIDEX4 & $126 \pm 5$ & $119 \pm 6$ & $94 \pm 6 *$ & $83 \pm 9 *$ & $92 \pm 5^{*}$ & $117 \pm 2$ \\
\hline & LIDEX8 & $133 \pm 3$ & $127 \pm 6$ & $104 \pm 3^{*}$ & $80 \pm 5^{*}$ & $78 \pm 4^{*}$ & $123 \pm 3$ \\
\hline DAP & $\mathrm{LI}$ & $67 \pm 6$ & $68 \pm 8$ & $43 \pm 5^{*}$ & $45 \pm 6^{*}$ & $47 \pm 5^{*}$ & $74 \pm 3$ \\
\hline & LIDEX2 & $75 \pm 4$ & $64 \pm 4$ & $58 \pm 5^{*}$ & $38 \pm 2^{*}$ & $54 \pm 7 *$ & $75 \pm 2$ \\
\hline & LIDEX4 & $83 \pm 5$ & $78 \pm 7$ & $51 \pm 5^{*}$ & $48 \pm 8^{*}$ & $54 \pm 4^{*}$ & $79 \pm 2$ \\
\hline & LIDEX8 & $88 \pm 7$ & $80 \pm 6$ & $61 \pm 4^{*}$ & $44 \pm 5^{*}$ & $53 \pm 2 *$ & $78 \pm 4$ \\
\hline MAP & $\mathrm{LI}$ & $86 \pm 6$ & $83 \pm 7$ & $61 \pm 6^{*}$ & $63 \pm 7^{*}$ & $63 \pm 3^{*}$ & $87 \pm 4$ \\
\hline & LIDEX2 & $101 \pm 4$ & $90 \pm 4$ & $81 \pm 7^{*}$ & $58 \pm 2^{*}$ & $70 \pm$ 6* & $91 \pm 2$ \\
\hline & LIDEX4 & $100 \pm 4$ & $95 \pm 5$ & $69 \pm 5^{*}$ & $63 \pm 8^{*}$ & $72 \pm 4^{*}$ & $94 \pm 1$ \\
\hline & LIDEX8 & $105 \pm 4$ & $98 \pm 5$ & $80 \pm 3^{*}$ & $59 \pm 5^{*}$ & $60 \pm 2 *$ & $98 \pm 4$ \\
\hline RT & $\mathrm{LI}$ & $39.0 \pm 0.2$ & $39.1 \pm 0.4$ & $38.8 \pm 0.4$ & $37.8 \pm 0.4^{*}$ & $37.1 \pm 0.3^{*}$ & $38.0 \pm 0.2 *$ \\
\hline & LIDEX2 & $39.1 \pm 0.2$ & $39.1 \pm 0.1$ & $38.5 \pm 0.3^{*}$ & $37.9 \pm 0.4^{*}$ & $37.0 \pm 0.2^{*}$ & $37.6 \pm 0.2 *$ \\
\hline & LIDEX4 & $38.3 \pm 0.3$ & $38.4 \pm 0.2$ & $37.4 \pm 0.1^{*}$ & $37.3 \pm 0.2^{*}$ & $36.8 \pm 0.2^{*}$ & $37.6 \pm 0.1^{*}$ \\
\hline & LIDEX8 & $38.9 \pm 0.2$ & $38.8 \pm 0.3$ & $38.0 \pm 0.3^{*}$ & $37.6 \pm 0.2^{*}$ & $37.1 \pm 0.2 *$ & $37.5 \pm 0.1^{*}$ \\
\hline
\end{tabular}

$\mathrm{T}_{0} \mathrm{iT}_{0}$ indicates basal, before premedication; $\mathrm{T}_{10}, 10 \mathrm{~min}$ after premedication; $\mathrm{T}_{20}, 20 \mathrm{~min}$ after TIVA; $\mathrm{T}_{30}, 30$ minmin after epidural injections; $T_{60}, 60$ min after epidural injections; $T_{120}, 120$ min after epidural injections; HR,HR, heart rate (beats/min); RR, respiratory rate (breaths/mi); SAP, systolic arterial pressure $(\mathrm{mm} \mathrm{Hg})$; DADAP, diastolic arterial pressure $(\mathrm{mm} \mathrm{Hg})$; MAP, mean arterial pressure (mm $\mathrm{Hg})$; RT, rectal temperature $\left({ }^{\circ} \mathrm{C}\left({ }^{\circ} \mathrm{C}\right) .{ }^{*} \mathrm{p}<0.05\right.$ by Least Squares Means test compared to basal. The values for LI, LIDEX2, LIDEX4 and LIDLIDEX8 did not differ $(p=0.075)$ among treatments within each time.

\section{- Discussion}

Our results suggest that dexamethasone administered by epidural route produces useful analgesia as observed by the increase of the time to first analgesic requirement in the immediate postoperative period in female dogs that underwent ovariohysterectomy. The postoperative pain observed in small animals after obstetric surgeries can be caused by more than one anatomical structure, and 
the pain may be considered to be visceral (deep) or somatic (superficial) ${ }^{22}$. In humans, epidural dexamethasone is significantly more effective than IV dexamethasone for reducing postoperative pain and requirement for analgesics following laparoscopic cholecystectomy ${ }^{1}$. However, no studies have investigated the effect of epidural dexamethasone treatment on postoperative pain after abdominal surgery in small animals.

The main finding of the current study was that adding dexamethasone $(8 \mathrm{mg})$ to epidural lignocaine induced a prolonged postoperative analgesic duration (19.5 (SD 6) hours) in female dogs undergoing $\mathrm{OVH}$. Similar results were obtained in humans with preoperative administration of dexamethasone (8 $\mathrm{mg}$ ) given by epidural route providing analgesic effects in patients undergoing abdominal hysterectomy ${ }^{11}$. Patients who received epidural dexamethasone either alone or combined with bupivacaine had a longer duration of postoperative analgesia and less analgesic consumption compared to a control group that received IV dexamethasone and epidural bupivacaine ${ }^{17}$. With regard to the potential mechanism for this effect, epidural dexamethasone interferes with the synthesis of intraspinal prostaglandin by inhibiting phospholipase A2 and the expression of cyclooxygenase 2. After surgical trauma, excitatory amino acids such as glutamate and aspartate are released from peripheral tissues. These activate the $\mathrm{N}$-methyl-D-aspartate receptors of the dorsal horn neurons in the spinal cord, with a consequent increase in the intracellular calcium ion which is needed for activation of the enzyme phospholipase A2, which mobilizes arachidonic acid. Almost immediately, the expression of cyclo-oxygenase 2 is up-regulated, triggering the release of prostaglandin E2, which results in a hyperalgesic state ${ }^{15}$.

The study reported here demonstrates that adding $8 \mathrm{mg}$ dexamethasone to epidural lignocaine in the preoperative period to female dogs undergoing $\mathrm{OVH}$ is more effective than adding either $2 \mathrm{mg}$ or $4 \mathrm{mg}$ dexamethasone to prolong postoperative analgesic duration. Previous studies in humans showed that lower doses of epidural dexamethasone may be effective in surgical procedures associated with mild or moderate pain such as laparoscopy, orchiopexy and herniorrhaphy ${ }^{1,10}$.

Although some surgeons are concerned that steroids impair healing, we must take into consideration that the biologic half-life of dexamethasone (36-58 hours) is less than the time required for a postoperative wound to heal, and wound healing takes approximately 1 week, by which time the steroid has been entirely cleared from the body ${ }^{23}$. In a human study, glucose levels remained unchanged after epidural administration of three doses $(4,6$, and $8 \mathrm{mg})$ of dexamethasone ${ }^{11}$. We did not conduct histological analyses nor did us measure glucose levels, but based on clinical examination none of the animals in this study had wound infection or delayed healing after surgery. The motor blockade time that occurred in all treatments was consistent with the duration of action of the local anaesthetic lignocaine. This effect disappeared during the period of evaluation in the postoperative analgesia. Dexamethasone is related with central nervous system-stimulating side effects such as agitation ${ }^{24}$. However, a brief period of sedation was observed in all dexamethasone treatments in our study. Due to this unexpected result, the analgesic effect of dexamethasone ${ }^{10}$ through systemic absorption may have influenced the assessment of sedation.

As the primary objective of this study was to establish a clinically effective and safe dose of dexamethasone into the epidural space to relieve postoperative pain in dogs after $\mathrm{OVH}$, animal euthanasia was not performed to observe possible injury in the meninges and spinal cord. Previous experimental studies with 
intrathecal but not epidural, administration of methylprednisolone and betamethasone at high doses and continuously showed dosedependent intrathecal inflammatory reactions in dogs $\mathrm{s}^{25-27}$. However, neuronal injuries, demyelination, or gliosis were not clinically observed in any animal in these studies. Another limitation of our study was the lack of measurement of blood glucose levels. The administration of a glucocorticoid is well known to reduce the hypoglycaemic effect of insulin and to interfere with blood glucose control in diabetic patients ${ }^{28}$. In humans, epidural dexamethasone at a dose of $8 \mathrm{mg}$ is not associated with increased glucose level or delayed wound healing ${ }^{11}$. Finally, our study included a small sample size, composed of six female dogs each group. Despite that fact, the study assesses successfully that the combination of the local anaesthetic lignocaine with dexamethasone might be useful in the relief of postoperative pain.

\section{Conclusions}

Epidural dexamethasone at $8 \mathrm{mg}$ combined with lignocaine was more effective to prolong postoperative analgesia in female dogs undergoing $\mathrm{OVH}$ than lower doses (2 or $4 \mathrm{mg}$ ). Cardiovascular changes were similar among all treatments but remained within acceptable limits. Dexamethasone usage had no side effects such as delayed wound healing or wound infection.

\section{References}

1. Thomas S, Beevi S. Epidural dexamethasone reduces postoperative pain and analgesic requirements. Can J Anaesth. 2006 Sep;53(9):899-905. doi: 10.1007/ BF03022833.

2. Hansen B.D. Assessment of pain in dogs: veterinary clinical studies. Ilar J. 2003;44(3):197-205. doi: 10.1093/ ilar.44.3.197.
3. DeRossi R, Jardim PHA, Hermeto LC, Pagliosa RC. Comparison of analgesic and systemic effects of bupivacaine, methadone, or bupivacaine/methadone administered epidurally in conscious sheep. Aust Vet J. 2015 May;93(5):164-9. doi: 10.1111/ avj.12313.

4. DeRossi R, Módolo TJ, Maciel FB, Pagliosa RC. Efficacy of epidural lignocaine combined with tramadol or neostigmine on perineal analgesia in the horse. Equine Vet J. 2013 Jul;45(4):497-502. doi: 10.1111/j.20423306.2012.00654.x.

5. Singh R, Kumar N, Singh P. Randomized controlled trial comparing morphine or clonidine with bupivacaine for caudal analgesia in children undergoing upper abdominal surgery. $\mathrm{Br} J$ Anaesth. 2011 Jan;106(1):96-100. doi: 10.1093/bja/ aeq274.

6. Peterson NW, Buote NJ, Bergman P. Effect of epidural analgesia with opioids on the prevalence of urinary retention in dogs undergoing surgery for cranial cruciate ligament rupture. J Am Vet Med Assoc. 2014 Apr 15;244(8):940-3. doi: 10.2460/ javma.244.8.940.

7. Kalchofner Guerrero KS, Guerrero TG, Schweizer-Kölliker M, Ringer SK, Hässig $M$, Bettschart-Wolfensberger R. Incidence of delayed hair re-growth, pruritus, and urinary retention after epidural anaesthesia in dogs. Tierarztl Prax Ausg K Kleintiere Heimtiere. 2014 Apr 16;42(2):94-100. PMID: 24737184.

8. Vesal N, Cribb PH, Frketic M. Postoperative analgesic and cardiopulmonary effects in dogs of oxymorphone administered epidurally and intramuscularly, and medetomidine administered epidurally: a comparative clinical study. Vet Surg. 1996 Jul-Aug;25(4):361-9. doi: 10.1111/j.1532950X.1996.tb01428.x.

9. de Beer DA, Thomas ML. Caudal additives in children - Solutions or problems? $\mathrm{Br}$ J Anaesth. 2003 Apr;90(4):487-98. doi: https://doi.org/10.1093/bja/aeg064.

10.Khafagy HF, Refaat Al, El-Sabae HH, Youssif MA. Efficacy of epidural dexamethasone versus fentanyl on postoperative analgesia. J Anesth. 2010 Aug;24(4):531-6. doi: 10.1007/s00540-010-0949-7. 
11.Hefni AF, Mahmoud MS, Al Alim AA. Epidural dexamethasone for post-operative analgesia in patients undergoing abdominal hysterectomy: a dose ranging and safety evaluation study. Saudi J Anaesth. 2014 Jul;8(3):323-7. doi: 10.4103/1658$354 X .136420$.

12.Yao XL, Cowan MJ, Gladwin MT, Lawrence MM, Angus CW, Shelhamer $\mathrm{H}$. Dexamethasone alters arachidonate release from human epithelial cells by induction of $\mathrm{p} 11$ protein synthesis and inhibition of phospholipase A2 activity. J Biol Chem. 1999 Jun 11;274(24):17202-8. PMID: 10358078.

13.Johansson A, Hao J, Sjölund B. Local corticosteroid application blocks transmission in normal nociceptive C-fibres. Acta Anaesthesiol Scand. 1990 Jul;34(5):335-8. doi: 10.1111/j.13996576.1990.tb03097.x.

14.Wilkinson IM, Cohen SP. Epidural steroids for spinal pain and radiculopathy: a narrative, evidence-based review. Curr Opin Anaesthesiol. 2013 Oct;26(5):562-72. doi: 10.1097/ACO.0b013e3283628e87.

15.Ebersberger A, Grubb BD, Willingale HL, Gardiner NJ, Nebe J, Schaible HG. The intraspinal release of prostaglandin E2 in a model of acute arthritis is accompanied by an up-regulation of cyclooxygenase- 2 in the spinal cord. Neuroscience. 1999;93(2):77581. doi: 10.1016/S0306-4522(99)00164-5.

16.Gan TJ, Meyer T, Apfel CC, Chung F, Davis PJ, Eubanks E, Kovac A, Philip BK, Sessler DI, Temo J, Tramèr MR, Watcha $M$. Consensus guidelines for managing postoperative nausea and vomiting. Anesth Analg. 2003 Jul;97(1):62-71. PMID: 12818945.

17.Jebaraj B, Khanna P, Baidya DK, Maitra S. Efficacy of epidural local anesthetic and dexamethasone in providing postoperative analgesia: a meta-analysis. Saudi J Anaesth. 2016 Jul-Sep;10(3):322-7. doi: 10.4103/1658-354X.179096.

18.Wang YL, Tan PP, Yang CH, Tsai SC, Chung HSL. Epidural dexamethasone reduces the incidence of backache after lumbar epidural anesthesia. Anesth Analg. 1997 Feb;84(2):376-8. PMID: 9024032.

19. Kim E J, Moon JY, Park KS, Yoo DH, Yong CK, Woo SS, Lee CJ, Shin HY, Kim JH, Kim YD, Lee SJ. Epidural steroid injection in Korean pain physicians: a national survey. Korean J Pain. 2014 Jan;27(1):35-42. doi: 10.3344/ kjp.2014.27.1.35.

20. Hansen B.D. Through a glass darkly: using behavior to assess pain. Semin Vet Med Surg (Small Anim). 1997 May;12(2):61-74. PMID: 9159063.

21.Brondani JT, Mama KR, Luna SPL, Wright BD, Niyon S, Ambrosio J, Vogel PR, Padovani $C R$. Validation of the English version of the UNESP-Botucatu multidimensional composite pain scale for assessing postoperative pain in cats. BMC Vet Res. 2013 Jul 17;9:143. doi: 10.1186/1746-61489-143.

22. Hsu HW, Cheng YJ, Chen LK, Wang YP, Lin CJ, Lee CJ, Sun CN, Less WZ. Differential analgesic effect of tenoxicam on the wound pain and uterine cramping pain after cesarean section. Clin J Pain. 2003 JanFeb;19(1):55-8. PMID: 12514457.

23.Pien LC, Grammer LC, Patterson R. Minimal complications in a surgical population with severe asthma receiving prophylactic corticosteroids. J Allergy Clin Immunol. 1988 Oct;82(4):696-700. doi: 10.1016/00916749(88)90985-2.

24.Vardy J, Chiew KS, Galica J, Pond GR, Tannock IF. Side effects associated with the use of dexamethasone for prophylaxis of delayed emesis after moderately emetogenic chemotherapy. $\mathrm{Br} J$ Cancer. 2006 Apr 10;94(7):1011-5. doi: 10.1038/ sj.bjc. 6603048 .

25. Barros GA, Marques ME, Ganem EM. The effects of intrathecal administration of betamethasone over the dog's spinal cord and meninges. Acta Cir Bras. 2007 Sep-Oct;22(5):361-5. doi: 10.1590/S010286502007000500007.

26.Lima RM, Navarro LH, Carness JM, Barros GA, Marques MEA, Solanki D, Ganem EM. Clinical and histological effects of the intrathecal administration of methylprednisolone in dogs. Pain Physician. 2010 Sep-Oct;13(5):493-501. PMID: 20859319.

27.Rijsdijk $M$, van Wijck AJ, Kalkman CJ, MeulenhoffPCW, GrafeMR,SteinauerJ,Yaksh TL. Safety assessment and pharmacokinetics of intrathecal methylprednisolone acetate in dogs. Anesthesiology. 2012 Jan;116(1):17081. doi: 10.1097/ALN.0b013e31823cf035. 
28. Munck A. Glucocorticoid inhibition of glucose uptake by peripheral tissues: old and new evidence, molecular mechanisms, and physiological significance. Perspect Biol Med. 1971 Winter;14(2):265-9. doi: 10.1353/pbm.1971.0002.

\section{- Acknowledgements}

To Dr. Gustavo G. Macedo for statistical advice, and to all the pet owners for gently providing their dogs for use in this study.

\section{Correspondence:}

\section{Rafael De Rossi}

Departamento de Medicina Veterinária, Cirurgia e Anestesiologia

Faculdade de Medicina Veterinária e Ciências

Animal, UFMS

Caixa Postal 549

79070-900 Campo Grande - MS Brasil

Tel.: (55 67)3345-3601

rafael.rossi@ufms.br

Received: Dec 04, 2016

Review: Feb 06, 2017

Accepted: March 11, 2017
Conflict of interest: none

Financial source: none

\begin{abstract}
${ }^{1}$ Research performed at Department of Surgery, Division of Operative Technique and Experimental Surgery, Universidade Federal do Mato Grosso do Sul (UFMS), Campo GrandeMS, Brazil.
\end{abstract}

